\title{
A high resolution AGCM study of the El Niño impact on the North Atlantic/European sector
}

\author{
Ute Merkel and Mojib Latif \\ Max-Planck-Institut für Meteorologie, Hamburg, Germany \\ Received 3 July 2001; revised 18 October 2001; accepted 2 November 2001; published 2 May 2002.
}

[1] An atmospheric general circulation model (AGCM) sensitivity study has been performed with the ECHAM4 model forced by anomalous sea surface temperatures to investigate the role of the horizontal resolution (T42 versus T106) in determining the El Niño/Southern Oscillation (ENSO) response in the North Atlantic/European region. The higher resolution has been chosen in order to represent more realistically the transient eddy activity that is supposed to play a crucial role in the signal communication to regions remote from the tropical Pacific. In contrast to the T42 experiments, the T106 experiments reveal significant changes both in the mean of selected atmospheric variables (sea level pressure, temperature, precipitation) over Europe and in the transient and stationary wave activity. A cyclone tracking analysis reveals a southward shift of the North Atlantic low pressure systems in the winter season during El Niño events. INDEX TERMS: 4215 Oceanography: General: Climate and interannual variability (3309); 4522 Oceanography: Physical: El Niño; 3309 Meteorology and Atmospheric Dynamics: Climatology (1620)

\section{Introduction}

[2] Numerous studies - both observational and modellinghave been performed in order to address the relationship between tropical Pacific sea surface temperature (SST) anomalies related to the interannual El Niño/Southern Oscillation (ENSO) phenomenon and global atmospheric circulation changes (see Trenberth et al. [1998] for a review). While the ENSO impact is well established over the Pacific Basin and in various regions surrounding it (e.g. Indonesia), the response in the North Atlantic/European sector is less well understood. However, it has been concluded from observational studies that a weak response may exist in some atmospheric quantities (sea level pressure, temperature, precipitation) during the winter season (DJF) of El Niño or La Niña events [Fraedrich and Müller, 1992; Fraedrich, 1994] or the following spring [van Oldenborgh et al., 2000]. Strong changes over Europe were reported by Dong et al. [2000] who investigated the El Niño/La Niña period of 1997-1999. Modelling studies (e.g. Ferranti et al. [1994]; Bengtsson et al. [1996]) have been inconclusive so far with respect to the ENSO response simulated in the European sector. To our knowledge, none of these ensemble experiments has been performed at a higher resolution than T63. However, evidence arises from the analysis of different models [Déqué and Piedelievre, 1995; Stendel and Roeckner, 1998; Branković and Gregory, 2001] that the simulated upper-air fields as well as precipitation patterns in the North Atlantic/European sector benefit from increased horizontal resolution. We therefore hypothesize that increased resolution in AGCM experiments may help to understand the processes that lead to an ENSO

Copyright 2002 by the American Geophysical Union. 0094-8276/02/2001GL013726 response over the Atlantic/European sector. In this study high resolution experiments are conducted in order to get further insight into the establishment of the ENSO response over the Atlantic/European region.

\section{Model and Experiments}

[3] We use the ECHAM4/T106 $\left(\sim 1.1^{\circ} \times 1.1^{\circ}\right)$ atmospheric general circulation model (AGCM) [Roeckner et al., 1996] with 19 vertical levels. In order to account for the internal variability of the atmosphere, the model is run in ensemble mode. Starting from different initial conditions, five members are conducted forced by the same anomalous SST pattern. The forcing pattern is derived from a regression analysis in which the global observed seasonal (DJF) SST anomalies are regressed onto the seasonal (DJF) Niño3 SST anomaly timeseries.

[4] The regression is based on the Reynolds SST dataset [Reynolds and Smith, 1994] and the period 1981-1998 which includes the strong El Niño events of 1982/83 and 1997/98. The resulting SST anomaly pattern exhibits the typical El Niño shape with positive anomalies in the eastern equatorial Pacific and negative anomalies to the north and south of it. Shown in Figure 1 is the regression pattern multiplied by a factor of 3, and these scaled anomalies are used as a forcing for the ECHAM4 model. To put things into perspective, the DJF SST anomaly composite corresponding to the discussion in Fraedrich and Müller [1992] was computed and found to be qualitatively similar. It should be noted, however, that our SST forcing is much stronger than the observed composite. Since we impose a "canonical" SST anomaly pattern, our study differs from those that have been performed by Dong et al. [2000] and Grötzner et al. [2000] who focussed onto the 1997/98 El Niño.

[5] Each realization has a duration of 120 days (Nov.-Feb.), but only the last 90 days (DJF) are analyzed. The results of this ensemble are compared to a similar control ensemble forced by climatological SST. In order to investigate the sensitivity of the results to the horizontal resolution, we performed analogous experiments (control ensemble, El Niño ensemble) with the ECHAM4 model run at T42 $\left(\sim 2.8^{\circ} \times\right.$ $2.8^{\circ}$ ) resolution.

\section{Results}

\subsection{Mean Response}

[6] The seasonal ensemble mean response of sea level pressure (El Niño minus control experiment) is presented in Figure 2 for both resolutions. The significance of the response is assessed by applying a standard two-tailed Student's $t$-test.

[7] In both cases, the Southern Oscillation signature is dominant in the Pacific region and significant negative anomalies are present over the North East Pacific and over parts of the United States. A considerable weakening of the meridional pressure gradient is simulated over the North Atlantic sector, implying a change in the North Atlantic Oscillation (NAO). 


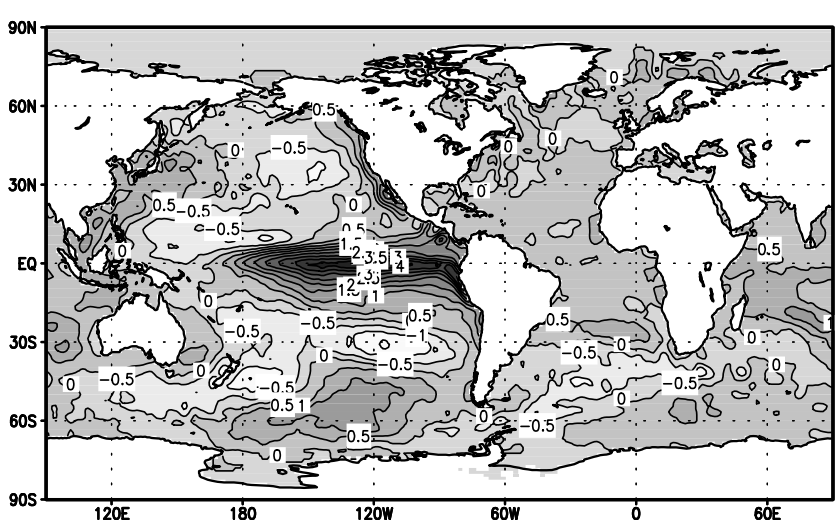

Figure 1. Regression of the global observed seasonal (DJF) SST anomalies onto the DJF Niño3 SST anomaly timeseries, scaled by a factor of 3. This pattern serves as anomalous SST forcing in the T42 and T106 experiments.

However, only in the T106 experiment, the two centers of action over the North Atlantic extend eastward into Europe, and a statistically significant response over most parts of Central Europe is simulated only at this resolution (Figure 2b). The extension of a significant response into Europe at T106 resolution is also present in other quantities such as the upper level zonal wind field (not shown). The latter exhibits a dipole-like structure with increased wind speeds spreading from Southern North America into South-Western Europe and reduced wind speeds further to the north.

[8] Comparing the response of various atmospheric variables over Europe to the observational results of Fraedrich and Müller [1992] reveals a qualitatively similar and partly significant anomaly structure in the T106 simulation (Figure 3), whereas the T42 results (not shown) bear no resemblance to the Fraedrich and Müller [1992] composites over the European continent. A quantitative correspondence of the anomalies displayed in Figure 3 cannot be expected due to the different strength of the forcing. The dominant role of the tropical Pacific is emphasized by a similar T106 experiment in which only the tropical Pacific part of the regression pattern shown in Figure 1a and climatological SST elsewhere was prescribed. It was found that the response of the tropical Pacific experiment was remarkably similar to the global regression experiment.

\subsection{Stormtracks and Eddy Activity}

[9] In order to get more insight into the simulated mean response of the T106 experiment, a cyclone tracking analysis is performed by means of a detection tool developed at the University of Hamburg [Blender et al., 1997]. Figure 4 presents the detected cyclone tracks of all T106 ensemble members during the DJF season. Especially over the central North Atlantic, higher cyclone density is simulated in the El Niño ensemble. This change corresponds to a southward shift of the North Atlantic stormtrack and is found to be significant at the $95 \%$ level within the region $30^{\circ} \mathrm{N}-45^{\circ} \mathrm{N}, 60^{\circ} \mathrm{W}-10^{\circ} \mathrm{W}$, according to the non-parametric Mann-Whitney-Wilcoxon test. The stormtrack displacement is also evident in the bandpassfiltered (2.5-6 days) transient eddy variance of the $500 \mathrm{hPa}$ geopotential height field, which depicts the stormtrack activity on synoptic timescales (not shown). The analysis of the lower tropospheric Eady growth rate [Hoskins and Valdes, 1990], a measure of baroclinicity, further elucidates these changes. Those regions characterized by a decrease in stormtrack activity during El Niño conditions consistently exhibit a reduction in the Eady growth rate, which can mainly be attributed to a response in the vertical shear of the time mean wind.

[10] From a nonlinear perspective, however, the mean flow itself is affected by changes in transient eddy activity. Therefore we analyze the large-scale response in terms of the barotropic energy conversions [Wallace and Lau, 1985] between the time mean zonal flow and the transient eddies. In both the bandpass-filtered (2.5-6 days) and lowpass-filtered (10-90 days) range the transient-eddy-mean-flow energy exchange is modified in the El Niño experiment. The climatological barotropic production of eddy kinetic energy over the North American continent is reduced, and may in part be related to a strengthening and a more downstream extension of the $200 \mathrm{hPa}$ jetstream. However, since baroclinic production processes might also play a role, no simple causal relationship can be established. The relative role of these processes in determining the mean flow response is subject of current investigations. We additionally analyzed the Plumb vector [Plumb, 1985], and it reveals a more zonal propagation of stationary wave activity in the North Atlantic sector compared to our control simulation.

\section{Discussion and Summary}

[11] We found evidence for the hypothesis that increased horizontal resolution might be one step towards simulating a weak but significant impact of the El Niño phenomenon on the North Atlantic/European sector, as seen in observations [Fraedrich and Müller, 1992]. Increased horizontal resolution enables a more realistic representation of the orography and therefore a better simulation of the stationary waves and the synoptic scale
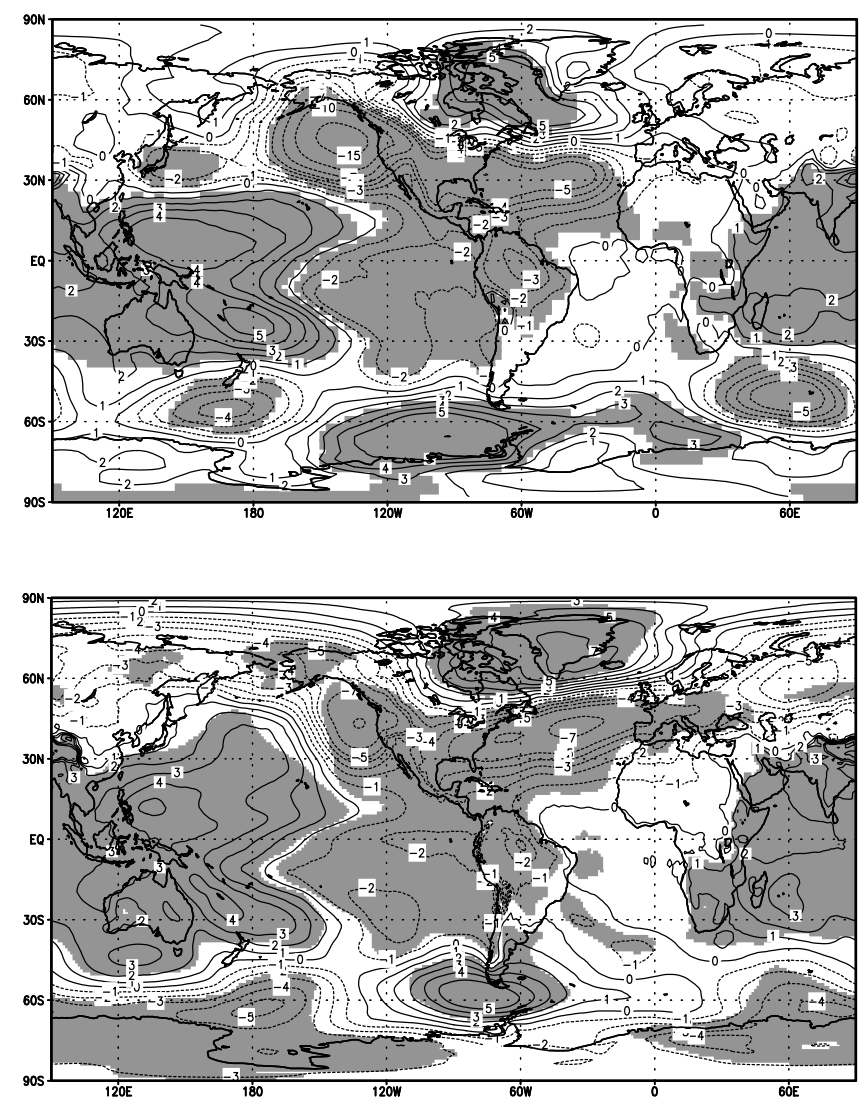

Figure 2. Seasonal (DJF) ensemble mean response of SLP [hPa]. Note the irregular contour spacing $(0, \pm 1,2,3,4,5,7,10,15 \mathrm{hPa})$. Shaded regions indicate significance at the $95 \%$ level according to a $t$-test. (a) T42 experiment, (b) T106 experiment. 

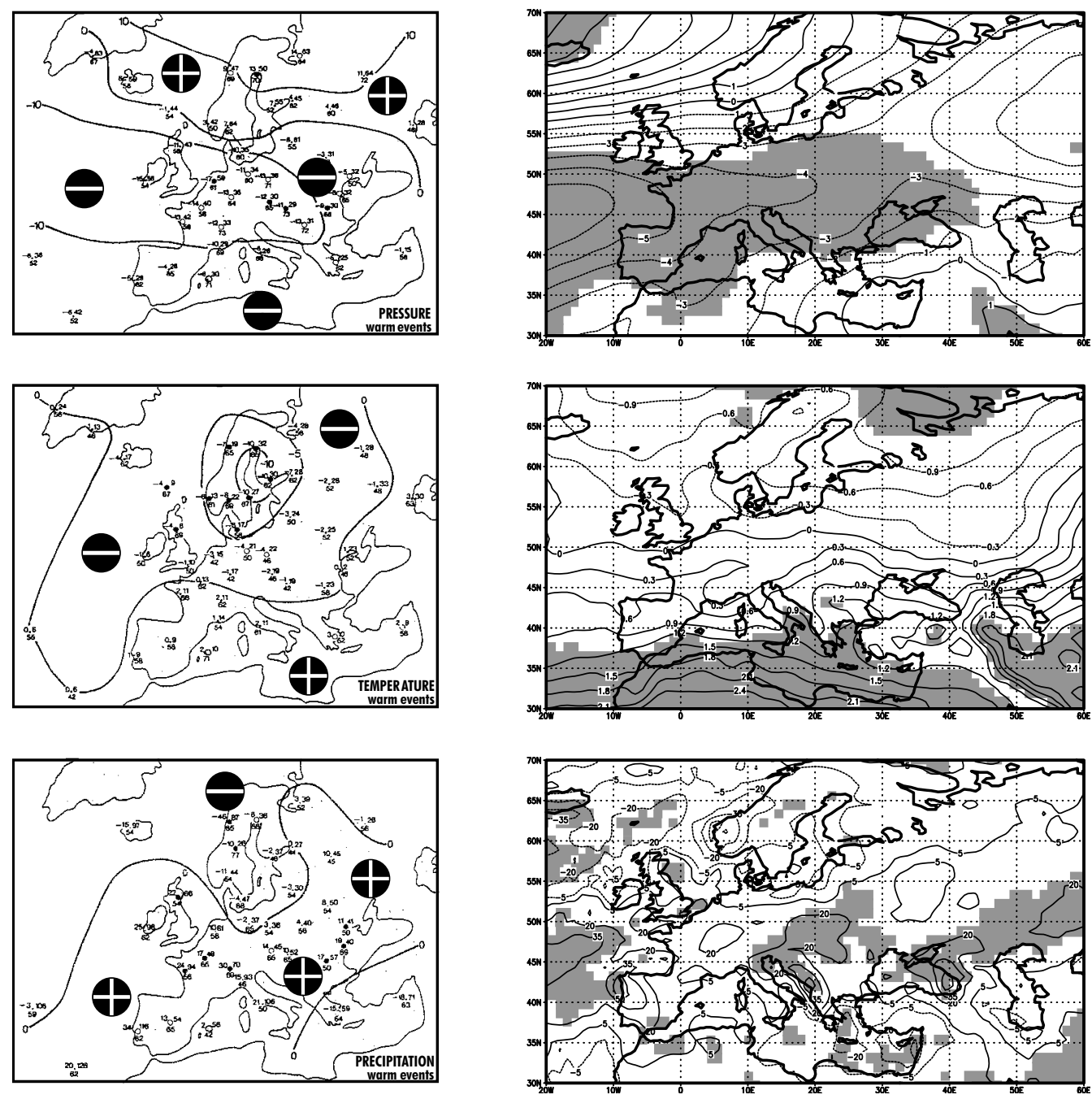

Figure 3. Right panels: Seasonal (DJF) ensemble mean response in the T106 experiment of SLP [hPa] (top), air temperature at $850 \mathrm{hPa}$ $[\mathrm{K}]$ (middle), precipitation [mm/month] (bottom). Shaded regions indicate significance on the 95\% level according to a $t$-test. For comparison, the results of the composite study by Fraedrich and Müller [1992] are redrawn on the left (units: [1/10 hPa], [1/10 K], [mm/ month], respectively; contour intervals: $1 \mathrm{hPa}, 0.5 \mathrm{~K}$, zero line only, respectively).

transient eddies. In particular, a major improvement due to higher resolution is achieved for the zonally asymmetric components [Stendel and Roeckner, 1998]. An improved representation of the North Atlantic wintertime general circulation with increased horizontal resolution has also been found in sensitivity studies with the ARPEGE AGCM [Déqué and Piedelievre, 1995]. Since the eddy-mean flow interaction is considered to be crucial in determining midlatitude dynamical processes, the qualitative and at least partly significant reproduction of the observational results over the North Atlantic/European sector in the T106 experiment (in contrast to T42) may be attributed to the higher horizontal resolution.

[12] We would like to emphasize that the simulated seasonal anomalies over Europe may only be interpreted as a "canonical" response pattern related to El Niño events. One has to take into account that the response in remote regions such as Europe might vary from event to event due to differences between El Niño events [Hamilton, 1988] and may be masked by the large internal variability of the atmosphere in midlatitudes [Kumar and Hoerling, 1997]. Large discrepancies, for instance, have been noticed between the observed DJF anomalies over Europe during the 1997/98 El Niño event and the Fraedrich and Müller [1992] composite picture. Furthermore, it still remains to be proven that the mean atmospheric response to La Niña events found by Fraedrich and Müller [1992] may be simulated in an analogous and successful manner.

[13] The North Atlantic Oscillation is a major factor in determining European weather and climate anomalies. It plays an important role for the tracks of the rain-bearing North Atlantic cyclones, which follow a more northerly route during positive NAO extreme winters. Our model results suggest an El Niño-related weakening of the North Atlantic mean meridional pressure gradient and a southward shift of the North Atlantic stormtrack. The simulated response over Europe is consistent with a weakening of the NAO, with wetter conditions over central Europe and the western Mediterranean, and colder temperatures over Scandinavia [Hurrell and van Loon, 1997]. There may exist, however, a decadal modulation of the signal communication between the Pacific and the Atlantic sectors [Raible et al., 2001], so that the seasonal relationship between the tropics and the North Atlantic shown here should also be considered within a low-frequency context.

[14] Acknowledgments. The authors are grateful to Drs. Scot Johnson and Noel Keenlyside and the two anonymous reviewers for their helpful comments on an earlier version of the paper. This work was supported by the European Union's DEMETER program. 

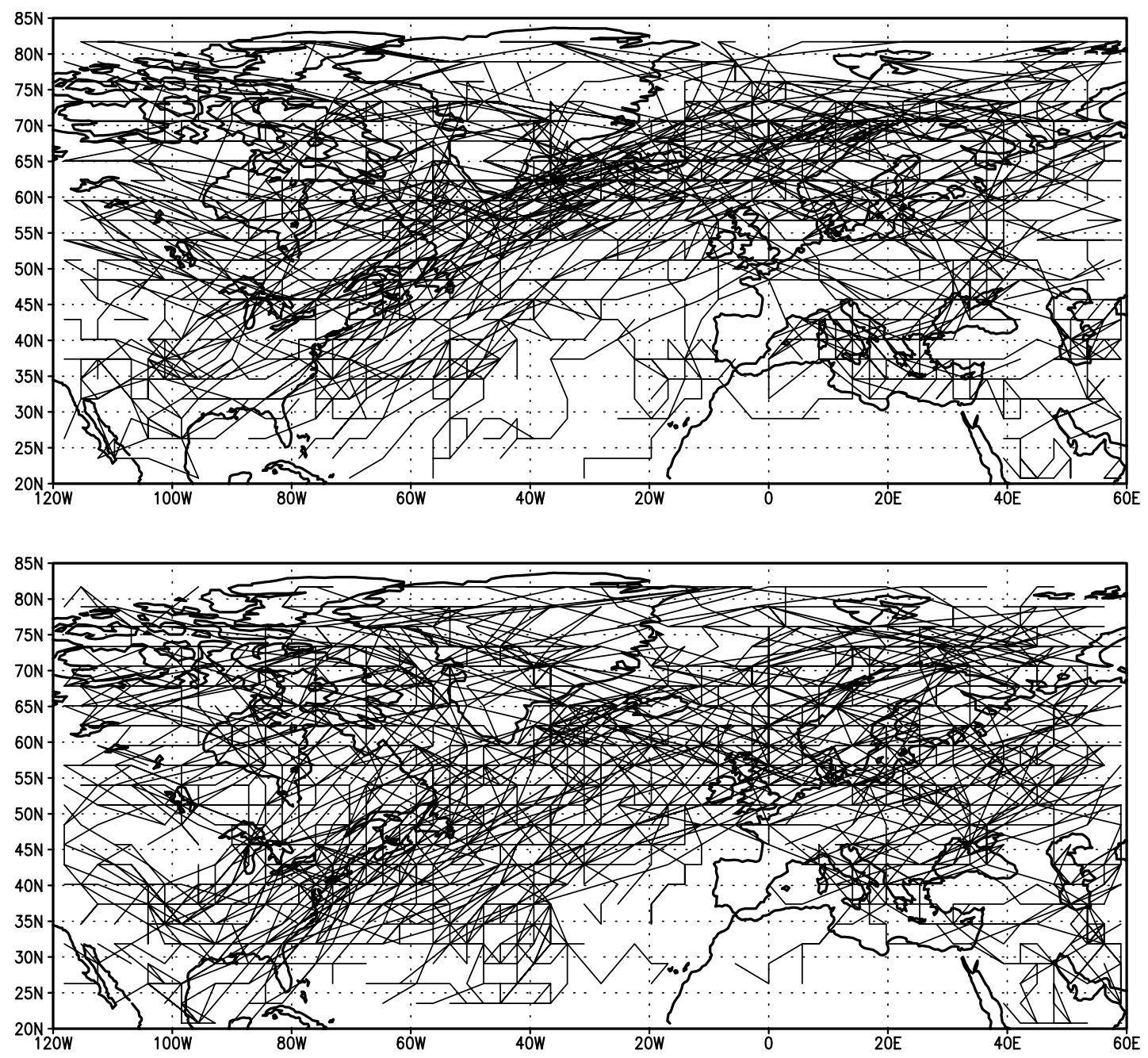

Figure 4. Cyclone tracks over the North Atlantic during DJF season from all ensemble members of (a) the T106 control ensemble and (b) the T106 El Niño ensemble.

\section{References}

Bengtsson, L., K. Arpe, E. Roeckner, and U. Schulzweida, 1996: Climate predictability experiments with a general circulation model, Clim. Dyn., $12,261-278,1996$

Blender, R., K. Fraedrich, and F. Lunkeit, Identification of cyclone-track regimes in the North Atlantic, Quart. J. R. Met. Soc., 123, 727-741, 1997.

Branković, C., and D. Gregory, Impact of horizontal resolution on seasonal integrations, Climate Dynamics, accepted, 2001.

Déqué, M., and J. P. Piedelievre, High resolution climate simulation over Europe, Clim. Dyn., 11, 321-339, 1995

Dong, B.-W., R. T. Sutton, S. P. Jewson, A. O’Neill, and J. M. Slingo, Predictable Winter Climate in the North Atlantic Sector During the 1997-1999 ENSO Cycle, Geophys. Res. Lett., 27, 985-988, 2000.

Ferranti, L., F. Molteni, and T. N. Palmer, Impact of localized tropical and extratropical SST anomalies in ensembles of seasonal GCM integrations, Quart. J. Roy. Met. Soc., 120, 1613-1645, 1994.

Fraedrich, K., and K. Müller, Climate Anomalies in Europe Associated With ENSO Extremes, Int. J. Climatol., 12, 25-31, 1992.

Fraedrich, K., An ENSO impact on Europe?, Tellus, 46A, 541-552, 1994

Grötzner, A., M. Latif, and D. Dommenget, Atmospheric response to sea surface temperature anomalies during El Niño 1997/98 as simulated by ECHAM4, Quart. J. Roy. Met. Soc., 126, 2175-2198, 2000.

Hamilton, K., A Detailed Examination of the Extratropical Response to Tropical El Niño/Southern Oscillation Events, J. Climatol., 8, 67-86, 1988 .

Hoskins, B. J., and P. J. Valdes, On the Existence of Storm-Tracks, J. Atm Sci., 47(15), 1854-1864, 1990 .

Hurrell, J. W., and H. van Loon, Decadal variations in climate associated with the North Atlantic Oscillation, Climatic Change, 36, 301-326, 1997.
Kumar, A., and M. P. Hoerling, Interpretation and Implications of the Observed Inter-El Niño Variability, J. Climate, 10(1), 83-91, 1997.

Plumb, R. A., On the Three-Dimensional Propagation of Stationary Waves, J. Atm. Sci., 42(3), 217-229, 1985

Raible, C., U. Luksch, K. Fraedrich, and R. Voss, North Atlantic decadal regimes in a coupled GCM simulation, Clim. Dyn., in press, 2001.

Reynolds, R. W., and T. M. Smith, Improved global sea surface temperature analyses using optimal interpolation, J. Climate, 7, 929-948, 1994.

Roeckner, E., K. Arpe, L. Bengtsson, M. Christoph, M. Claussen, L. Dümenil, M. Esch, M. Giorgetta, U. Schlese, and U. Schulzweida, The atmospheric general circulation model ECHAM-4: Model description and simulation of present-day climate, Max-Planck-Institut für Meteorologie, Hamburg, Report no. 218, 90 pp., 1996.

Stendel, M., and E. Roeckner, Impacts of horizontal resolution on simulated climate statistics in ECHAM4, Max-Planck-Institut für Meteorologie, Hamburg, Report no. 253, 57 pp., 1998.

Trenberth, K. E., G. W. Branstator, D. Karoly, A. Kumar, N.-C. Lau, and C. F. Ropelewski, Progress during TOGA in understanding and modelling global teleconnections associated with tropical sea surface temperatures, J. Geophys. Res., 103, 14,291-14,324, 1998.

van Oldenborgh, G. J., G. Burgers, and A. Klein-Tank, On the El Niño teleconnection to spring precipitation in Europe, Int. J. Climatol., 20, $565-574,2000$

Wallace, J. M., and N.-C. Lau, On the role of barotropic energy conversions in the general circulation, Advances in Geophysics, 28(Part A), 33-74, 1985 .

U. Merkel and M. Latif, Max-Planck-Institut für Meteorologie, Bundesstr. 55, D-20146 Hamburg, Germany. (merkel@dkrz.de) 